Research Paper

\title{
Mapping ecosystem services for China's ecoregions with a biophysical surrogate approach
}

\author{
Liwei Zhang ${ }^{\mathrm{a}}$, Yihe Lü ${ }^{\mathrm{b}, *}$, Bojie Fu ${ }^{\mathrm{b}}$, Zhibao Dong ${ }^{\mathrm{a}, \mathrm{c}}$, Yuan Zeng ${ }^{\mathrm{d}}$, Bingfang $\mathrm{Wu}^{\mathrm{d}}$ \\ a Department of Geography, Tourism and Environment College of Shaanxi Normal University, Xi'an, Shaanxi 710119, China \\ b State Key Laboratory of Urban and Regional Ecology, Research Center for Eco-Environmental Sciences, Chinese Academy of Sciences, Beijing 100085, China \\ c Cold and Arid Regions Environmental and Engineering Research Institute, Chinese Academy of Sciences, No. 322, West Donggang Road, Lanzhou, Gansu \\ 730000, China \\ ${ }^{\mathrm{d}}$ Institute of Remote Sensing and Digital Earth, Chinese Academy of Sciences, Beijing 100094, China
}

\section{H I G H L I G H T S}

- Biophysical indicators were formulated to map ecosystem services (ESs) in China.

- These indicator-based models can reveal the relative order of ESs required for large-scale mapping.

- Land-use change plays a critical role in the significant increase of total ESs in China from 2000 to 2010.

\section{A R T I C L E I N F O}

\section{Article history:}

Received 2 November 2015

Received in revised form

26 December 2016

Accepted 31 December 2016

Available online 28 January 2017

\section{Keywords:}

Ecosystem services mapping

Biophysical indicator

Spatial pattern

Temporal trends

Ecoregions

China

\begin{abstract}
A B S T R A C T
Spatially explicit mapping of ecosystem services (ESs) is an essential step in drawing up policies and practices designed to improve human well-being by ensuring the sustainable provision of ESs. This study used a set of quantitative surrogate biophysical indicators to map the capability of China's eleven ecoregions to provide four types of ESs (carbon capture, soil protection, water purification and provision, and habitat provision) from 2000 to 2010. The results revealed the spatial distribution patterns and time trends of the ESs of the eleven ecoregions in China. This study shows that: (1) the average annual total value of ESs provided from 2000 to 2010 increased from northwest to southeast, and in the Middle and lower reaches of the Yangtze River as well as over the entirety of the Yunnan-Guizhou Plateau and South China ecoregions; (2) the temporal trends of annual total ESs from 2000 to 2010 showed increases in most ecoregions except those of northeast China and northern China, which experienced decreases; and (3) the surrogate biophysical method for mapping the spatial and temporal characteristics of ESs gives acceptable results, especially at large spatial scales, compared to research results obtained using more complex modeling approaches. Thus the simple surrogate approach is suitable for the rapid assessment and long-term dynamic surveillance of ESs at broad spatial scales, and for tasks such as priority setting or performance assessments for nature conservation and ecological restoration with ESs as key targets. The methodology is also suitable for land-use impact analysis and trade-off analysis concerning land-use decisions in terrestrial environments.
\end{abstract}

(C) 2017 Elsevier B.V. All rights reserved.

\section{Introduction}

Ecosystem services (ESs) are those critical benefits that people receive from natural ecosystems and help to sustain and support human well-being (MEA, 2005). The concept of ESs is increasingly considered pivotal in research into ecological conservation and restoration, land-use management, urban planning and the assess-

\footnotetext{
* Corresponding author.

E-mail address: lyh@rcees.ac.cn (Y. Lü).
}

ment of ecosystem sustainability - research that covers the policy and decision making arenas (Bateman et al., 2013; Cowling et al., 2008; Daily et al., 2009; MEA, 2005; Trabucchi, Ntshotsho, O’Farrell, \& Comín, 2012; Woodruff \& BenDor, 2016; Zagonari, 2016). However, projects to safeguard ESs can only be successful if these ESs can be quantified and mapped (Naidoo et al., 2008). Providing the spatially explicit information in maps of key areas supplying ESs is an essential step in the process of drawing up policies that will incorporate ESs into land management, thereby ensuring the sustained supply of ESs and their associated benefits to humans (Burkhard Crossman, Nedkov, Petz, \& Alkemade, 2013; Cowling et al., 2008; 
Daily \& Matson, 2008). Maps of ESs are important communication tools for the stakeholders and decision-makers responsible for land-use planning, because maps enable them to locate those ecosystems which provide high value services (Balvanera et al., 2001; Maes et al., 2013). Although ES maps are helpful tools in the processes of decision-making, a number of challenges will be encountered in their use. These challenges relate to the credibility, salience, and legitimacy of the maps (Hauck et al., 2013). Moreover, the targets, costs, spatiotemporal scales, assessment methods and data availability for the decision-making project significantly impact the accuracy of ES maps (Eigenbrod et al., 2010). Although it is clear that actual investment in and implementation of an environmental plan typically occur at local scales, research and analysis at broad scales can provide decision-makers with macroscopic information and will benefit resource and action prioritization in ecosystem management at broad scales.

Regional or national scale, studies have commonly mapped ESs using surrogate models based on well-known causal relationships between environmental factors; most of these studies were based on secondary data, without the use of validation techniques (Alam, Dupras, \& Messier, 2016; Martínez-Harms \& Balvanera, 2012). Clearly, the spatially explicit mapping of ESs at a broad scale is significantly limited by data and model availability as well as by the difficulty of validating mapping results. However, these limitations do not lessen the overwhelming demand from stakeholders and decision-makers for evaluations of the spatial patterns and temporal variations of ESs - it is their crucial natural capital. For example, Action 5 of the European Union (EU) Biodiversity Strategy to 2020 requires all Member States to map the state of ESs within their national territories; the assessment results are designed to help resolve complex public issues in the EU (Maes et al., 2013). To meet this demand, the surrogate method deploys knowledge about the relationship between environmental variables and ESs to create new surrogate indicators for ES mapping that can be applied at multiple scales (Alam et al., 2016). This method can improve the mapping of ESs when primary data are absent, but the effectiveness of this method depends on how well the environmental variables determining the distribution of ESs are understood (Martínez-Harms \& Balvanera, 2012).

In this study, we use a set of surrogate models to map four types of key ESs in China. They were chosen because of their importance in the conservation of ESs at the national scale (Lü, Ma, Zhang, Fu, \& Gao, 2013; Ouyang et al., 2016), namely: carbon capture by vegetation, soil protection, water purification and provision, and habitat provision. The objectives of the present research include: (1) adapting a biophysically-based simple surrogate approach for mapping four types of key ESs at the national scale during the period from 2000 to 2010; (2) revealing the spatial pattern of the four types of ESs and the year-to-year trends of the sum-total of these ESs with reference to the eleven ecoregions of China; and (3) analyzing the potential driving factors of ES variation in the specific ecoregions of China. We also discuss the usability of the surrogate approach.

\section{Study area}

This study is focused on China, a country with an area of about 9.6 million square kilometers and, in 2015, a population of 1.38 billion people. Climate, altitude, and vegetation type vary significantly across China. The climate ranges from cold temperate in the north, through warm temperate, to equatorial tropical in the south (Wu, Yang, \& Zheng, 2003; Zheng, Yin, \& Li, 2010). The altitude also increases greatly from east to west, with the Qinghai-Tibet Plateau located in southwest China having an average altitude of over four thousand meters above sea level. The diverse range of forest types also varies from north to south, and includes coniferous and decid- uous forests, broad-leaved mixed forests, deciduous broad-leaved forests, mixed evergreen forests, broad-leaved forests, seasonal rainforests, and rainforests (Fu, Liu, Lü, Chen, \& Ma, 2004; Wu et al., 2003). Following Bailey $(1983,1988)$ China can be divided into eleven "ecoregions" (Fig. 1), where an ecoregion is defined as a large ecosystem of regional extent or a geographical zone that accommodates associations of similarly functioning ecosystems. Based on the work of Xie et al. (2012), the regions are classified according to their temperature, precipitation, altitude, vegetation index, geomorphological conditions and administrative boundaries. These ecoregions are used as a spatial framework for analyzing the broad spatial patterns and temporal trends of the ESs in China.

\section{ES quantifying methods}

\subsection{Surrogate models}

The net primary production (NPP) of vegetation provides the energy that underpins nearly all terrestrial (as well as marine) ecosystems and is a key functional indicator. Directly or indirectly, NPP supports the lives of multiple species as well as maintaining healthy biodiversity and enhancing the efficiency of ecological processes (Maes et al., 2013; MEA, 2005; Zurlini et al., 2014). It is a critical surrogate indicator of ecosystem function and has been shown to be linked with the overall value of ESs (Costanza et al., 1998). Because many ESs are correlated with NPP and tend to shift in concert with it, NPP also governs the flow of many provisioning and regulating services and some cultural services (Costanza et al., 1997, Costanza, Fisher, Mulder, Liu, \& Christopher, 2007; Richmond, Kaufmann, \& Mynen, 2007; Zurlini et al., 2014). NPP also provides a fundamental supportive service because it represents a measure of the solar energy captured by ecosystems and which drives their overall functioning (Costanza et al., 2007; MEA, 2005; Zurlini et al., 2014). Egoh et al. (2008) evaluated the relationships between five ESs in South Africa, and they revealed that the NPP was positively correlated with four services, namely: surface-water flow regulation, water supply, soil accumulation and soil protection. Petrosillo, Semeraro, and Zaccarelli (2013), Aretano used the NPP as an indicator that quantifies multiple ESs, such as the production of timber and farm produce. The NPP can be readily estimated by combining a remotely sensed vegetation index with other pertinent environmental variables to reveal spatiotemporal characteristics at broad spatiotemporal scales (Potter et al., 1993; Yuan et al., 2014; Zhu, Pan, \& Zhang, 2007).

Carreño, Frank, and Viglizzo (2012) formulated a simple biophysical method for estimating relative changes in the capability of ecosystems to provide services following land-use changes in Argentina. This method has been expanded by Barral and Oscar (2012) to evaluate ESs relating to land-use planning in the southeast pampas of Argentina. Both methods used biophysical data, such as biomass or NPP, surface-water area, soil infiltration capacity, slope, precipitation, temperature, and elevation. They also described the theoretical basis and evaluated the results of the approaches before putting these indicators into practical analyses. However, the method is site-specific and needs to be adapted when used in other places. Carreño et al. (2012) used the environmental variables of biomass and its stability, precipitation, temperature and altitude above sea level to map the spatial patterns of the habitat provision ES in Argentina. They assumed that the capability of one biome to provide habitat is high when biomass and water are abundant, temperature is moderate to high, and altitude above sea level is low. However, in China over thousands of years, cultivation and increase in population have led to the severe degradation of the habitat of many species in the plains and lowland areas (Lei, Zhao, \& Yin, 2006; López-Pujol, Zhang, \& Ge, 2006; Zhang \& Ma, 


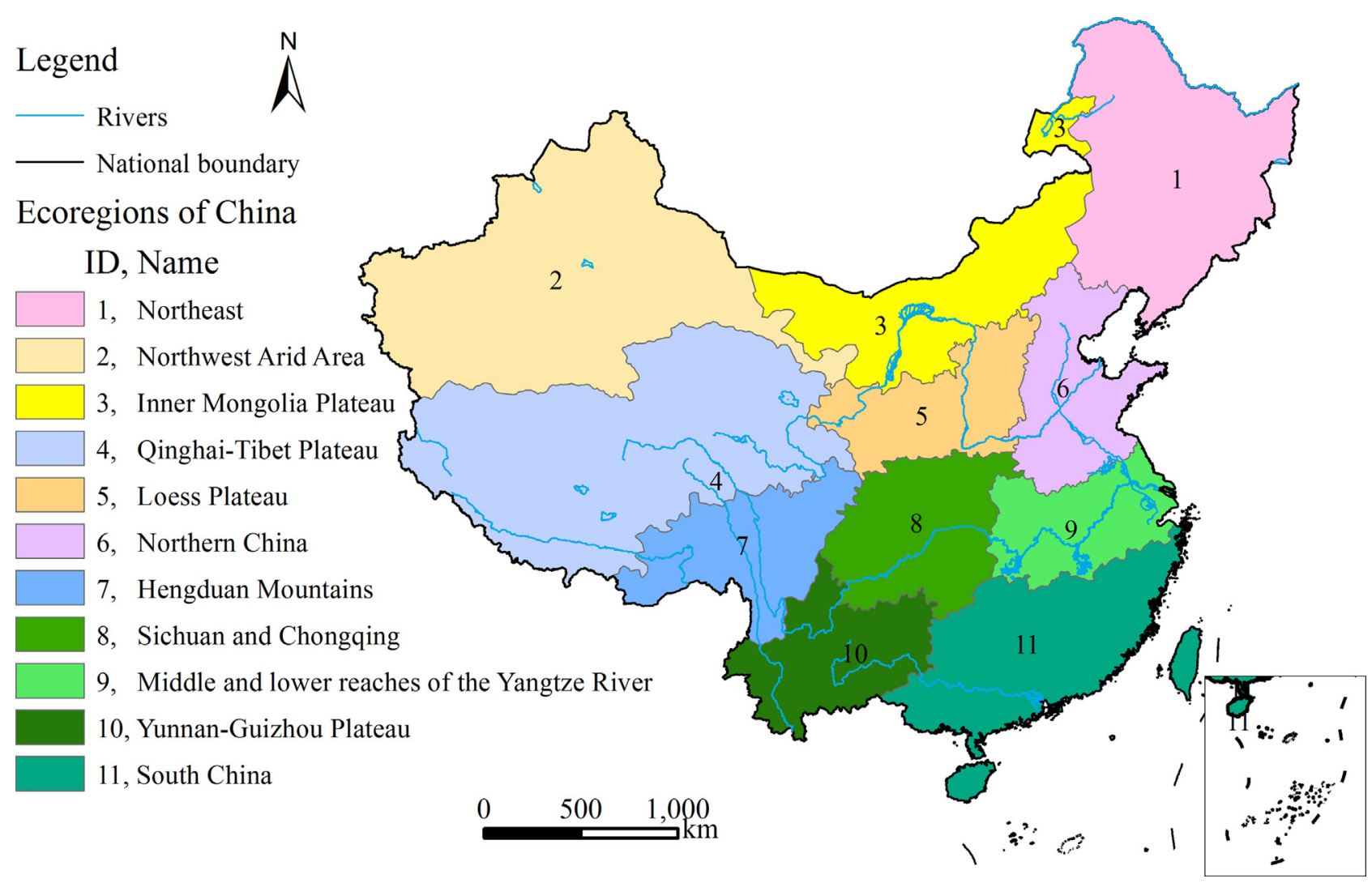

Fig. 1. Locations of ecoregions in China.

Table 1

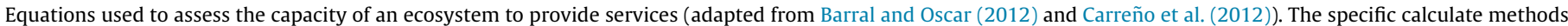
are gives in the 3.2 Sections.

\begin{tabular}{|c|c|c|}
\hline Ecosystem services & Equations & Variables \\
\hline Carbon capture & $N P P \times\left(1-V C_{n p p}\right)(1)$ & $\begin{array}{l}N P P \text { : the net primary productivity of } \\
\text { vegetation; } \\
V C_{n p p} \text { : the standard deviation factor of NPP } \\
\text { within a year; } \\
K: \text { soil erodibility factor; dimensionless. } \\
F_{\text {slo }} \text { : slope; } \\
F_{s i c} \text { : soil infiltration capacity; }\end{array}$ \\
\hline Soil protection & $\begin{array}{l}N P P \times\left(1-V C_{n p p}\right) \times(1-K) \times\left(1-F_{\text {slo }}\right) \\
(2)\end{array}$ & $\begin{array}{l}F_{\text {pre }}: \text { precipitation; } \\
F_{\text {tem }}: \text { temperature; }\end{array}$ \\
\hline $\begin{array}{l}\text { Water purification and provision } \\
\text { Habitat provision }\end{array}$ & $\begin{array}{l}N P P \times\left(1-V C_{\text {npp }}\right) \times F_{\text {sic }} \times F_{\text {pre }} \times\left(1-F_{\text {slo }}\right)(3) \\
N P P \times\left(1-V C_{\text {np }}\right) \times F_{\text {pre }} \times F_{\text {tem }} \times D(4)\end{array}$ & $D$ : surface roughness; \\
\hline
\end{tabular}

2008). On the other hand, mountain regions still harbor large numbers of species, because there has been less human disturbance and there are more diverse habitats (Tang, Wang, Zheng, \& Fang, 2006). Furthermore, topography plays an important role as a surrogate variable to explain vegetation-type diversity (Pérez, Mas, Velázquez, \& Vázquez, 2008), and the mountains of China are the nation's most important hotspots of biodiversity (Chen \& Peterson, 2002; Huang et al., 2012; Wu et al., 2014). We, therefore, developed a large-scale surrogate biophysical approach (Table 1 ) by adapting and revising those from Barral and Oscar (2012) and Carreño et al. (2012).

Based on the above, the carbon-capture capacity of vegetation in a region was mapped using the mathematical product of NPP and its variations within a year in Eq. (1) in Table 1. In similar fashion, to the product of NPP and its variations within a year, a soil erodibility factor, and land surface slope were used to create a composite surrogate indicator for mapping soil protection in Eq. (2) of Table 1 . The product of NPP and its variations within a year, soil infiltration capacity, annual precipitation and land surface slope was used as a composite surrogate indicator to map water purification and provision, see Eq. (3) of Table 1. Finally, the product of NPP and its variations within a year, land surface roughness, annual precipitation and temperature was used as a composite surrogate indicator to map habitat provision in Eq. (4) of Table 1. A land surface roughness factor was brought into the mapping method for habitat provision to reflect the distribution of China's mountains as biodiversity hotspots. The results of the surrogate approach used in this paper for mapping habitat provision can integrate information about vegetation patterns and topography.

\subsection{Calculation of the surrogate model variables}

1 NPP: The terrestrial Carnegie Ames-Stanford Approach (CASA) model was used to estimate NPP (Potter et al., 1993). CASA calculates NPP as (Feng, Fu, Lu, Zeng, \& Wu, 2013): 
$N P P(a, t)=\operatorname{APAR}(a, t) \times \varepsilon(a, t)$

where $\operatorname{NPP}(x, t)\left(\mathrm{g} \mathrm{C} \mathrm{m}^{-2} \mathrm{yr}^{-1}\right)$ is the rate of net primary production at location $a$ at time $t, \operatorname{APAR}(a, t)\left(\mathrm{MJ} \mathrm{m}^{-2} \mathrm{~s}^{-1}\right)$ is the rate of photosynthetically active radiation absorbed at location $a$ at time $t$, and $\varepsilon(a, t)$ $\left(\mathrm{gC} \mathrm{MJ}^{-1}\right)$ is the light-use efficiency of the vegetation at location $a$ at time $t$. The data requirements for the CASA model include land cover, normalized difference vegetation index (NDVI), and climate data. Summing the result of Eq. (5) over a year gives the annual total NPP $\left(\mathrm{gC} \mathrm{m}^{-2} \mathrm{yr}^{-1}\right)$.

$2 V C_{n p p}$ : The variable $V C_{n p p}$ is the standard deviation of the NPP within a year, which was calculated using the ENVI 5.0 (ESRI) software.

$3 F_{s l o}$ : Factor $F_{\text {slo }}$ is calculated by the Spatial Analyst module of ArcGIS 10.2(ESRI) software using digital elevation model (DEM) data (see Table 2).

4 Fsic: The soil infiltration capacity factor of $F_{\text {sic }}$ is based on the classification of soil texture by the USDA (United States Department of Agriculture), whereby soil particles are classified into 13 categories (FAO, 2009). In ascending order, they are clay (heavy), silty clay, clay, silty clay loam, clay loam, silt, silt loam, sandy clay, loam, sandy clay loam, sandy loam, loamy sand and sand. The factor $F_{\text {sic }}$ is assigned a value from $1 / 13,2 / 13, \ldots$, to 1 , based on the classification of the soil particles in ascending order.

5 Fpre and Ftem: The annual precipitation and temperature were interpolated by the Kriging method in the Geostatistical Analyst module of ArcGIS10.2 software, using meteorological data from 825 stations in China. $F_{\text {pre }}$ and $F_{\text {tem }}$ are factors normalized by the difference between the maximum and minimum values for annual precipitation and temperature from the year 2000-2010, respectively. $\mathrm{F}_{\text {pre }}$ and $\mathrm{F}_{\text {tem }}$ thus vary between 0 and 1 .

$6 K$ : The $K$ factor, soil erodibility, is calculated from the EPIC (Erosion-Productivity Impact Calculator) equation (Sharpley and Williams, 1990):

$$
\begin{aligned}
k= & \left\{0.2+0.3 e\left[-0.0256 s_{a}\left(1 \frac{s_{i}}{100}\right)\right]\right\}\left(\frac{s_{i}}{c_{l}+s_{i}}\right)^{0.3}\left\{1.0-\frac{0.25 C}{\left[C+e^{(3.72+2.95 C)}\right\}}\right\} \\
& \left\{1.0-\frac{0.7\left(1-\frac{s_{a}}{100}\right)}{\left(1-\frac{s_{a}}{100}\right)+e^{\left(-5.51+22.91-\frac{s_{a}}{100}\right)}}\right\}
\end{aligned}
$$

where $K$ is the soil erodibility, and $s_{a}, s_{i}, s_{l}$ and $c$ are the percentages of sand, clay, silt, and organic matter in soil, respectively.

$7 \mathrm{D}$ : The land surface roughness factor, $D$, is calculated as $D=1 / \cos (\theta)$, where $\theta$ is the radian of the slope. Both $D$ and $\theta$ are calculated by the Spatial Analyst module of ArcGIS10.2 software using DEM data.

Except for NPP, all the variables are normalized by the difference between the maximum and minimum values of the data range from the years 2000-2010, and therefore vary between 0 and 1 ; the annual values of the total ESs are the sum of these four ESs and their units are dimensionless. All the data and materials used to map the four types of ES and their parameters are presented in Table 2.

\subsection{Linear trend analysis of ES variations}

Linear regression was used to detect trends in vegetation and climate (see Lü et al., 2015). The least-squares regression model can be expressed as follows:

$y=c \times z+b+\delta$

$$
c=\frac{\sum_{i=1}^{n} i \times E S_{i}-\left(\sum_{i=1}^{n} i\right)\left(\sum_{i=1}^{n} E S_{i}\right) / n}{\sum_{i=1}^{n} i^{2}-\left(\sum_{i=1}^{n} E S_{i}\right)^{2} / n}
$$

In Eqs. (7) and (8), $y$ is the dependent variable of the annual ES in year $z$ ( $z$ ranges from 2000 to 2010, $\mathrm{t} \in \mathrm{N}$ ); $c$ is the linear trend of the ES and $b$ is the intercept of Eq. (7); and $\delta$ is the random error. $n$ is the total number of years $(n=11) . E S_{i}$ is the ES in year $i$. The raster maps of the linear trend (c) of each $E S_{i}$ can be calculated by Eq. (8) in ArcGIS10.2 software.

\section{Results}

\subsection{Spatial patterns of ES}

As shown in Fig. 2a-c, and e, the overall spatial patterns show carbon capture, soil protection, and water purification and provision increasing from the northwestern to the southeastern parts of China. The hotspots of habitat provision are clustered in the mountain areas (Fig. 2d). Statistical analysis (Table 3) shows that the lowest mean and sum-total values of annual carbon capture are found in both the Northwest Arid Area and the Inner Mongolia Plateau ecoregions; while the highest mean and sum-total values of annual carbon capture are in the Yunnan-Guizhou Plateau and South China ecoregions. The lowest mean and sum-total values of annual soil protection are found in the Northwest Arid Area and the Inner Mongolia Plateau ecoregions, while the highest mean and sum-total values of annual soil protection are seen in the South China ecoregion. The lowest mean and sum-total values of annual water purification and provision occur in the Northwest Arid Area ecoregion; while the highest mean and sum-total values of annual water purification and provision are seen the South China ecoregion. The lowest mean and sum-total values of the annual habitat provision ES are found the Inner Mongolia Plateau ecoregion; while the highest mean and sum-total values of the annual habitat provision ES are in the Yunnan-Guizhou Plateau and South China ecoregions. The lowest mean and sum-total values of annual sumtotal ESs appear in the Northwest Arid Area and the Inner Mongolia Plateau ecoregions, while the highest mean and sum-total values of annual sum-total ESs are seen the South China ecoregions.

\subsection{Temporal trends in total ES}

The annual sum-total ES decreased in the Northeast China and Northern China ecoregions, and the average decreases of the total ES in Northeast China and Northern China were about -2.33 per year and -3.29 per year, respectively. However, the other nine ecoregions experienced increases in total ES, with South China showing the greatest increase of 4.33 per year (Table 3). Even though, there were still significant variations in the trends of ESs within the ecoregions. Specifically, the annual total ES in the northern part of Northeast China and Northwest Arid Area, the southern part of the Qinghai-Tibet Plateau and Loess Plateau, the central part of the Yunnan-Guizhou Plateau and most of the Northern China ecoregions decreased significantly, while the north of the Loess Plateau ecoregions increased significantly. No significant change trends were detected in the rest parts of the ecoregions of China (Fig. 2f).

\subsection{Driving factors for the variations of total ESs}

Climate change, and land-use or land-cover change caused by human activities significantly influence the supply of ESs to 

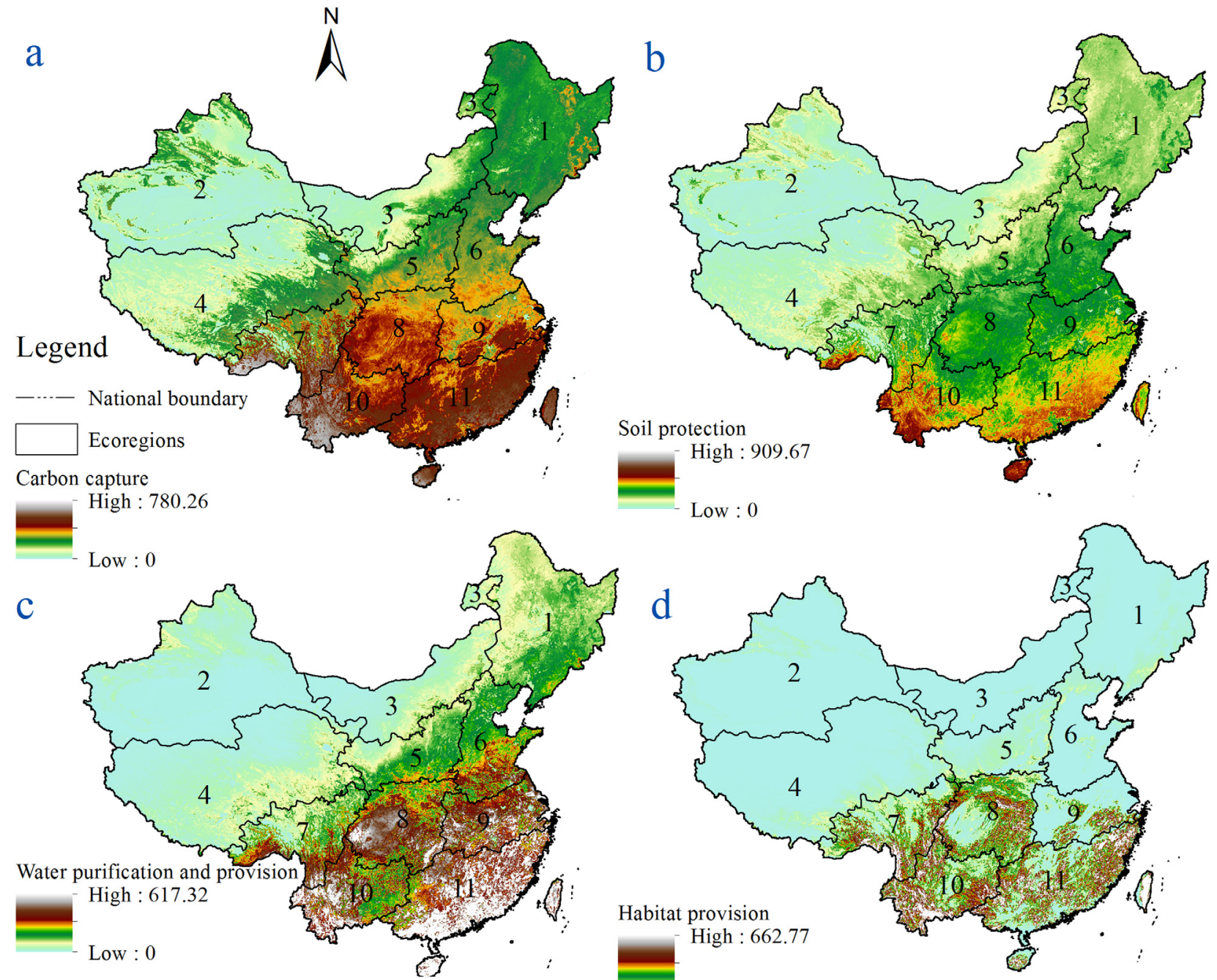

Low : 0

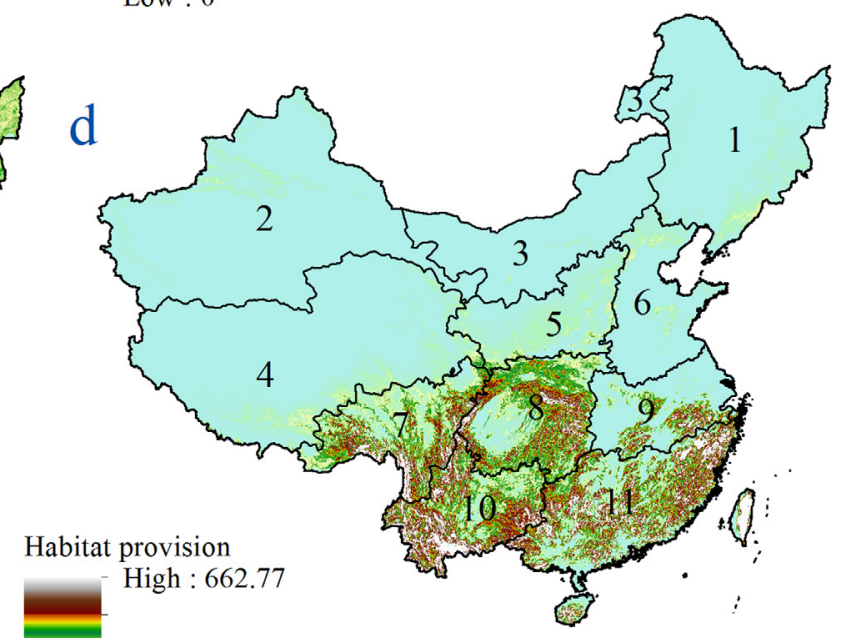

High : 662.77

Low : 0

e

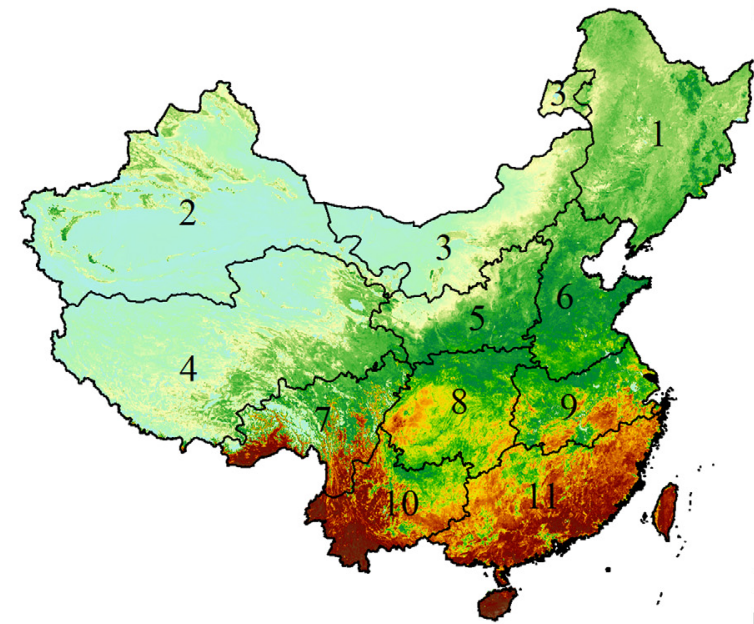

Sum of annual total ESs

High : 2183.22

Low : 0
, 3

$$
\text { 1, }
$$

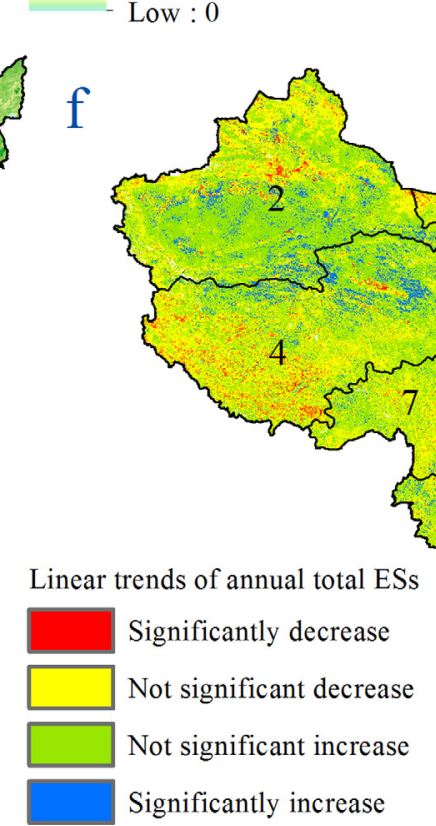

Fig. 2. Spatial distributions and linear trends of ecosystem services in China from 2000 to 2010. Fig. 2a-d shows the spatial patterns of soil protection, habitat provision, water purification and provision, and habitat provision ESs, which are the average of the annual single ES from 2000 to 2010. Fig. 2e shows the sum of the average of the annual four types from 2000 to 2010. Fig. 2f presents the linear trends of annual total ES from 2000 to 2010. The significance of the linear trends of annual total ES is based on the Pearson correlation coefficient of ESs and its time series. If the significance (P) of the Pearson correlation coefficient is lower than 0.05 , it means the linear trends of the annual total ESs are confidently based on the significance level and the values which are larger or lower than 0.The linear trends are classified into four categories: significant decrease $(P<0.05)$ and linear trends $(a<0)$, not changes $(a=0)$, not significant decrease $(P>0.05$ and $a<0)$, not significant increase $(P>0.05$ and $a>0)$, and significant increase $(\mathrm{P}<0.05$ and $\mathrm{a}>0)$. 
Table 2

The datasets used to map ESs and their parameters.

\begin{tabular}{|c|c|c|c|c|}
\hline Datasets & Data type & Original spatial resolution & Time scale & Data sources \\
\hline Meteorological data & Point & - & $2000-2010$ & http://cdc.cma.gov.cn/ \\
\hline DEM & Raster & $90 \mathrm{~m}$ & 2000 & http://srtm.csi.cgiar.org \\
\hline MODIS NDVI & Raster & $250 \mathrm{~m}$ & 2000-2010 & http://ladsweb.nascom.nasa.gov/data/ \\
\hline Soil properties & Raster & $1 \mathrm{~km}$ & 2009 & http://westdc.westgis.ac.cn \\
\hline
\end{tabular}

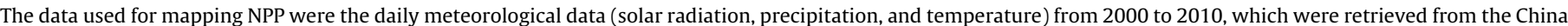

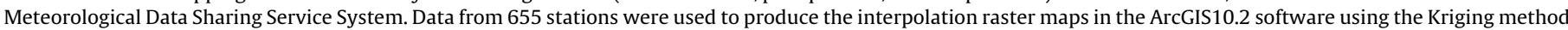

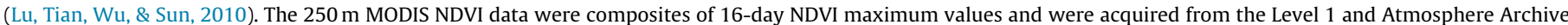

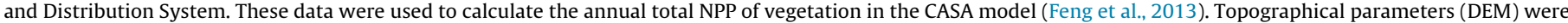

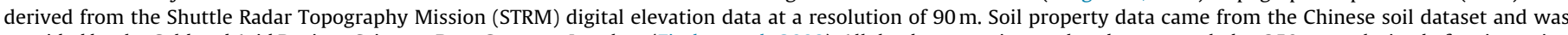

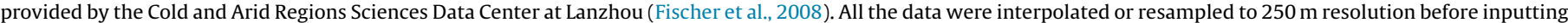
them into the models for further analysis.

Table 3

Statistical characteristics and linear trends of the ESs in the eleven ecoregions.

\begin{tabular}{|c|c|c|c|c|c|c|c|c|c|c|c|}
\hline \multirow{2}{*}{ ID } & \multicolumn{2}{|r|}{$\mathrm{CC}$} & \multicolumn{2}{|r|}{ SP } & \multicolumn{2}{|c|}{ WPP } & \multicolumn{2}{|r|}{ HP } & \multicolumn{2}{|c|}{ TES } & LT of TES \\
\hline & MEAN & SUM & MEAN & SUM & MEAN & SUM & MEAN & SUM & MEAN & SUM & MEAN \\
\hline 1 & 236 & $4.32 \mathrm{E}+09$ & 177 & $3.23 \mathrm{E}+09$ & 32 & 5.77E+08 & 0.14 & $2.54 \mathrm{E}+06$ & 445 & $8.12 \mathbb{E}+09$ & \\
\hline 2 & 73 & 2.09E+09 & 54 & $1.54 \mathrm{E}+09$ & 3 & |9.43E+07 & 0.06 & | 1.84E+06 & 131 & $3.71 \mathrm{E}+09$ & \\
\hline 3 & $\square 129$ & $167 \mathrm{E}+09$ & 104 & 1. $34 \mathrm{E}+09$ & 11 & ॥1.48E+08 & 0.02 & | $2.49 \mathrm{E}+05$ & 244 & 3. $16 \mathrm{E}+09$ & \\
\hline 4 & $\square 128$ & $3.64 \mathrm{E}+09$ & 90 & $2.55 \mathrm{E}+09$ & 10 & $2.79 \mathrm{E}+08$ & 0.22 & | $6.35 \mathrm{E}+06$ & 229 & $6.47 \mathrm{E}+09$ & 0 \\
\hline 5 & 259 & 2.07E+09 & 178 & 1. $43 \mathrm{E}+09$ & 37 & $2.95 \mathrm{E}+08$ & 0.68 & | $5.48 \mathrm{E}+06$ & 475 & 3. $80 \mathrm{E}+09$ & 1 \\
\hline 6 & 304 & $2.46 \mathrm{E}+09$ & 231 & $1.87 \mathrm{E}+09$ & 59 & 4.78E+08 & 0.22 & | $1.76 \mathrm{E}+06$ & 596 & $4.82 \mathrm{E}+09$ & \\
\hline 7 & 402 & $3.52 \mathrm{E}+09$ & 233 & $2.04 \mathrm{E}+09$ & 150 & 4.35E +08 & 6.09 & $5.33 \mathrm{E}+07$ & 691 & $6.04 \mathrm{E}+09$ & \\
\hline 8 & 419 & $3.91 \mathrm{E}+09$ & 275 & $2.56 \mathrm{E}+09$ & 96 & $8.98 \mathrm{E}+08$ & 6.14 & $5.73 \mathrm{E}+07$ & 796 & $7.43 E+09$ & \\
\hline 9 & 394 & $2.78 \mathrm{E}+09$ & 292 & $2.06 \mathrm{E}+09$ & 106 & $7.46 \mathrm{E}+08$ & 2.37 & $1.68 \mathrm{E}+07$ & 795 & $5.59 \mathrm{E}+09$ & \\
\hline 10 & 563 & $4.65 \mathrm{E}+09$ & 373 & $3.07 \mathrm{~B}+09$ & 105 & $8.68 \mathrm{E}+08$ & 10.14 & $8.36 \mathrm{E}+07$ & 1052 & $8.66 \mathrm{E}+09$ & 0 \\
\hline 11 & 526 & $7.53 \mathrm{E}+09$ & 376 & $5.35 \mathrm{E}+09$ & 151 & $2.14 \mathrm{E}+09$ & 8.57 & $1.22 \mathrm{E}+08$ & 1064 & $1.51 \mathrm{E}+10$ & 433 \\
\hline
\end{tabular}

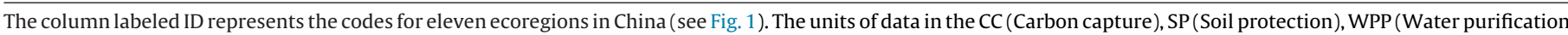

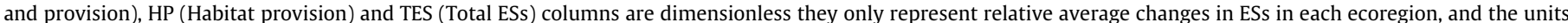

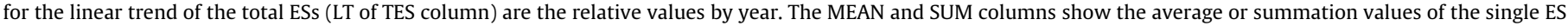
or total ESs of each ecoregion from 2000 to 2010. The length of the color bars in the table represents the sequence position of the value in its column.

human beings (Dunford, Smith, Harrison, \& Hanganu, 2015; Stürck, Poortinga, \& Verburg, 2014). The decline of sum-total ES in the south of the Qinghai-Tibet Plateau, the central part of YunnanGuizhou Plateau, the north of Northwest Arid Area and the east of the Inner Mongolia Plateau ecoregions was caused by the climate factors. The correlations between sum-total ESs and annual temperature were negative, and those between sum-total ESs and annual precipitation were positive. Furthermore, both the annual temperature increased and the annual precipitation decreased in these ecoregions (Fig. 3). However, the land-use types changed slightly or did not change into other land-use types (Liu et al., 2010). Liu et al. (2014) suggesting that the impact of external factors, such as climate change, on the degradation of vegetation in the ecoregions will induce a decrease in ESs. Also, land-use changes imposed pressures on the supply of ESs by ecosystems. The decline of total ESs in the north of Northeast China were partly because of climate changes, but the land-use changes in this ecoregion were also very fast from 2000 to 2010. In Northeast China, the main types of land-use change were from forest to farmland. In the south of the Loess Plateau and the Northern China ecoregions urban land use expanded very rapidly (Liu et al., 2010, 2014). Thus, in these regions, ESs decreased with the loss of natural land cover. In the north of the Loess Plateau ecoregion, where farmland was converted to grassland or forest under the promotion of the Grain for Green Project, vegetation in the area recovered significantly (Lü et al., 2015), and therefore the ESs of this area also increased significantly (Fig. 2f).

\section{Discussion}

\subsection{Evaluation of the ESs mapping models}

The effectiveness of ES mapping to inform decision-making is largely dependent on the availability of spatially explicit data and assessment methods (Crossman et al., 2013). At broad scales, such as provincial and national scales, it is a challenging task to map or quantify the spatiotemporal variations of ESs, especially in the context of scarce data. Oreskes, Shrader-Frechette, and Belitz (1994) pointed out that it is hard, or even impossible, to verify numerical models of natural systems because the sets of equations are never closed and the models therefore contain empirical constants. Model results are thus always site-specific. Although models can be verified by the consistency between observations and predictions, this validation is essentially partial (Carreño et al., 2012). Traditionally, complex process models have been widely used to map ESs at large scales, such as the InVEST models which integrate many process sub-models into their software systems, such as the universal soil loss equation (USLE) that is used for mapping soil conservation and the Budyko assumption used for mapping water provision (Budyko, 1974; Daily et al., 2009; Zhang, Dawes, \& Walker, 2001; Zhang, Fu, Lü, \& Zeng, 2015). However, most of the parameters in these models were derived from long-term observations from field experiments at small spatial scales; observations at large spatial scales, are scarce, and the methodology needs simplification when implemented at large spatial scales. However, this 


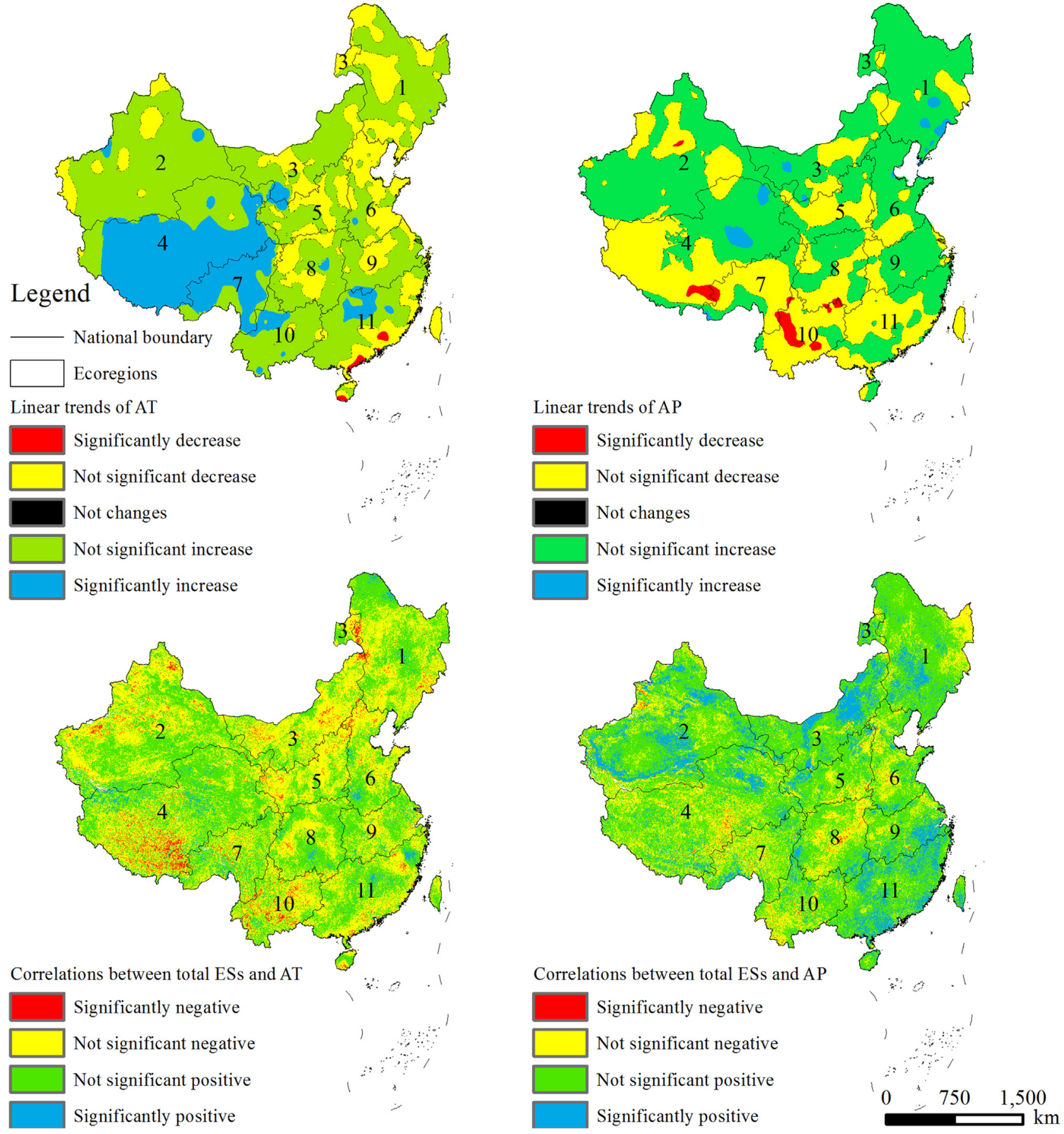

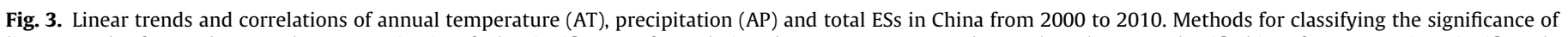

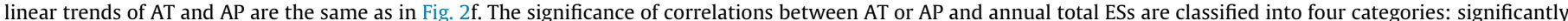

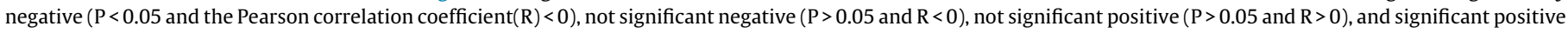
$(\mathrm{P}<0.05$ and $\mathrm{R}>0)$.

kind of simplification of model parameters will lead to uncertainty in quantifying ESs. Model validation is also problematic at large spatial scales (Carreño et al., 2012; Posner, Verutes, Koh, Denu, \& Ricketts, 2016). In practice, models only can be evaluated in relative terms and we have adopted that approach here.

The CASA model has been widely used to model the spatial distribution of NPP, with validation only when the results could be tested by comparison with field observation data. In China, the CASA model has been frequently used in research to characterize the NPP of vegetation (Gao et al., 2012; Zhu et al., 2007). The modeling results of NPP in this paper were evaluated against observational data from Yuan et al. (2014), allowing the spatial mapping of carbon capture by vegetation in China to be tested. Soil protection has usually been estimated using USLE-based models (Rao, Ouyang, Yu, \& Xiao, 2014; Wickama, Masselink, \& Sterk, 2015). Rao et al. (2014) used the USLE model to quantify the soil conservation service of ecosystems in China, and they found that southeast China generally displayed a much higher level of soil protection than northwest China, and this was much higher in the mountainous areas such as the Tsinling, Nanling, and Wuyi Mountains. As for impacts, the spatial variation of the soil conservation efforts in China were primarily controlled by climate and 
terrain at the national scale. Liu et al. (2013) employed the processbased Boreal Ecosystem Productivity Simulator (BEPS) model in conjunction with a set of environmental variables to simulate daily evapotranspiration and water yield at a spatial resolution of $500 \mathrm{~m}$ over China for the period from 2000 to 2010. They point out that the capacity of the water purification ES decreased moving from southeast to northwest China, and variations in the capacity of water purification and provision were significantly impacted by land-cover changes. The spatial characteristics of soil protection capacity revealed by Rao et al. (2014) and the capacity of the water purification and provision ES revealed by Liu et al. (2013) confirmed the results obtained by using the surrogate approach as an indicator for mapping ESs at China's national scale in this paper.

The NPP-based surrogate model can now be verified by using the complex processes models at the national scale in China to simulate mean annual NPP (Yuan et al., 2014), endemic plant richness (Qiu, Shen, Peng, Mao, \& Zhang, 2014), lizard species richness (Huang et al., 2012), the spatial distribution of mean evapotranspiration and water yield (Liu et al., 2013), and the soil protection service of ecosystems (Rao et al., 2014). Specifically, the spatial pattern of the annual total ESs could be also indirectly verified by the integrated national ecological security maps produced from complex ecological function modeling of freshwater provision, flood regulation, desertification control, soil erosion control, and biodiversity conservation (Yu, Li, Li, Qiao, \& Xi, 2009). More recently, Ouyang et al. (2016) used multiple process-based models of ES improvement and degradation hotspots to identify the spatial patterns of carbon sequestration and the overall importance of ESs at the national scale in China. These patterns were found to be similar to the trend detection and spatial pattern mapping results of the relevant ESs in this paper (Fig. 2a, e, f) by the NPP-based models. Based on the above discussion, we believe that the surrogate methods in this paper have a solid foundation of ecological theory and application. They are appropriate indicators for efficiently mapping the spatial patterns and temporal variations of ESs at large spatial scales. Importantly, the surrogate methods in this paper are simpler and more cost-effective for large-scale implementation.

\subsection{Usability of the surrogate ESs mapping approach}

The model equations employed here for mapping the four types of ESs were based on the combination of NPP and its variation, annual temperature and precipitation, slope and roughness of land surface, and soil infiltration capacity and erodibility of soils. Although at a large spatial scale the surrogate causal relationship models as used in this paper reveal relative rankings rather than the specific amounts of ESs found by using more complex modeling approaches, they are sufficient to meet the requirements of priority setting for conservation or land-use management. This is true not only because of the stable relationships between these ESs and multiple environmental variables, but also because remote sensing based estimates of NPP are employed in mapping ESs. Feng, Fu, Yang, and Lü (2010) suggested that remote sensing is an efficient methodology when applied to assessing ESs. For example, remote sensing data can directly monitor some plant and water related ESs, and can provide surrogate information on plant and soil characteristics of ecosystems, as well as spatially explicit measurements of ecosystem processes related to ESs. Despite limitations associated with the timing of assessment campaigns and the field data requirements, remote sensing offers valuable data for continuous mapping of ecosystem properties and can thus supply useful proxies for ESs (Homolová et al., 2014).

Consequently, the surrogate methodology developed in this paper can be used in many ways. For example, it can be used in the trade-off analysis between ESs and the economic benefits produced by changes in land-use policies (Carreño et al., 2012), thereby informing land-use assessment. The spatially explicit characteristics and cross-scale application of the indicators highlight their general applicability in developing land-use policies. For example, Barral and Oscar (2012) used the NPP-based surrogate model to evaluate seven types of ESs on land-use planning in the pampas of southeastern Argentina. They were able to propose the key regions needing to be protected by ES regulation. In addition, the surrogate models can be used during the priority-setting process (i.e., considering the conservation of both biodiversity and ESs) with the incorporation of ecosystem type and ecosystem diversity. For example, they can rank importance of the assessed ESs - sufficient to meet the needs of conservation prioritization. Moreover, the method will enhance the representation of key ESs areas.

\section{Conclusion}

The spatially explicit mapping of ESs is an essential step toward incorporating ESs into policymaking and to thereby ensure the continuous production of ESs and their associated benefits to humans. Applying remote sensing data to map ESs is an effective way to identify the spatial and temporal dynamics of ESs. The surrogate models provided in this paper for mapping ESs can reveal the relative order rather than specific amounts of ESs that might be obtained by using more complex modeling approaches. However, this ranking of services is sufficient to set priorities in ecological conservation and land-use management practice. We believe that using surrogate biophysical indicators to map the spatial and temporal characteristics of ESs is a reliable, and particularly swift way to quantitatively assess and monitor ESs at broad spatial scales.

\section{Acknowledgements}

This work was funded by the Ministry of Environmental Protection of China (201409055), the National Natural Science Foundation of China (41601182), the China Postdoctoral Science Foundation (2016M592743), the Fundamental Research Funds for the Central Universities (GK201603078), and the National Key Research and Development Plan of China (2016YFC0501601).

\section{References}

Alam, M., Dupras, J., \& Messier, C. (2016). A framework towards a composite indicator for urban ecosystem services. Ecological Indicators, 60, 38-44. http:// dx.doi.org/10.1016/j.ecolind.2015.05.035

Bailey, R. (1983). Delineation of ecosystem regions. Environmental Management, 7(4), 365-373. http://dx.doi.org/10.1007/BF01866919

Bailey, R. (1988). Ecogeographic analysis: A guide to the ecological division of land for resource management. Miscellaneous publication/United States. Dept. of Agriculture (USA). no. 1465.

Balvanera, P., Daily, G. C., Ehrlich, P. R., Ricketts, T. H., Bailey, S. A., Kark, S., et al. (2001). Conserving biodiversity and ecosystem services. Science, 291(5511), 2047. http://dx.doi.org/10.1126/science.291.5511.2047

Barral, M. P., \& Oscar, M. N. (2012). Land-use planning based on ecosystem service assessment: A case study in the Southeast Pampas of Argentina. Agriculture, Ecosystems \& Environment, 154, 34-43. http://dx.doi.org/10.1016/j.agee.2011. 07.010

Bateman, I. J., Harwood, A. R., Mace, G. M., Watson, R. T., Abson, D. J., Andrews, B., et al. (2013). Bringing ecosystem services into economic decision-making: Land use in the United Kingdom. Science, 341(6141), 45-50. http://dx.doi.org $10.1126 /$ science. 1234379

Budyko, M. I. (1974). Climate and life. San Diego, California: Academic Press.

Burkhard, B., Crossman, N., Nedkov, S., Petz, K., \& Alkemade, R. (2013). Mapping and modelling ecosystem services for science, policy and practice. Ecosystem Services, 4, 1-3. http://dx.doi.org/10.1016/j.ecoser.2013.04.005

Carreño, L., Frank, F. C., \& Viglizzo, E. F. (2012). Tradeoffs between economic and ecosystem services in Argentina during 50 years of land-use change. Agriculture, Ecosystems \& Environment, 154, 68-77. http://dx.doi.org/10.1016/j. agee.2011.05.019

Chen, G., \& Peterson, A. T. (2002). Prioritization of areas in China for the conservation of endangered birds using modelled geographical distributions. Bird Conservation International, 12, 197-209. http://dx.doi.org/10.1017/ S0959270902002125 
Costanza, R., d'Arge, R., de Groot, R. S., Farber, S., Grasso, M., Hannon, B., et al. (1997). The value of the world's ecosystem services and natural capital. Nature, 387, 253-260. http://dx.doi.org/10.1038/387253a0

Costanza, R., d’Arge, R., de Groot, R., Farber, S., Grasso, M., Hannon, B., et al. (1998). The value of ecosystem services: Putting the issues in perspective. Ecological Economics, 25, 67-72. http://dx.doi.org/10.1038/387253a0

Costanza, R., Fisher, B., Mulder, K., Liu, S., \& Christopher, T. (2007). Biodiversity and ecosystem services: A multi-scale empirical study of the relationship between species richness and net primary production. Ecological Economics, 61, 478-491. http://dx.doi.org/10.1016/j.ecolecon.2006.03.021

Cowling, R. M., Egoh, B., Knight, A. T., O’Farrell, P. J., Reyers, B., Rouget, M., et al. (2008). An operational model for mainstreaming ecosystem services for implementation. Proceedings of the National Academy of Sciences of the United States of America, 105(28), 9483-9488. http://dx.doi.org/10.1073/pnas. 0706559105

Crossman, N. D., Burkhard, B., Nedkov, S., Willemen, L., Petz, K., Palomo, I., et al. (2013). A blueprint for mapping and modelling ecosystem services. Ecosystem Services, 4, 4-14. http://dx.doi.org/10.1016/j.ecoser.2013.02.001

Daily, G. C., \& Matson, P. A. (2008). Ecosystem services: From theory to implementation. Proceedings of the National Academy of Sciences of the United States of America, 105(28), 9455-9456. http://dx.doi.org/10.1073/pnas. 0804960105

Daily, G. C., Polasky, S., Goldstein, J., Kareiva, P. M., Mooney, H. A., Pejchar, L., et al. (2009). Ecosystem services in decision making: time to deliver. Frontiers in Ecology and the Environment, 7, 21-28. http://dx.doi.org/10.1890/080025

Dunford, R. W., Smith, A. C., Harrison, P. A., \& Hanganu, D. (2015). Ecosystem service provision in a changing Europe: Adapting to the impacts of combined climate and socio-economic change. Journal of Landscape Ecology, 30(3), 1-19. http://dx.doi.org/10.1007/s10980-014-0148-2

Egoh, B., Reyers, B., Rouget, M., Richardson, D. M., Maitre, D. C. L., \& Jaarsveld, A. S. V. (2008). Mapping ecosystem services for planning and management. Agriculture Ecosystems E' Environment, 127(1), 135-140. http://dx.doi.org/10. 1016/j.agee.2008.03.013

Eigenbrod, F., Armsworth, P. R., Anderson, B. J., Heinemeyer, A., Gillings, S., Roy, D. B., et al. (2010). The impact of proxy-based methods on mapping the distribution of ecosystem services. Journal of Applied Ecology, 47(2), 377-385. http://dx.doi.org/10.1111/j.1365-2664.2010.01777.x

FAO. (2009). Harmonized world soil database (version 1.1). Rome, Italy and IIASA, Laxenburg, Austria: FAO.

Feng, X., Fu, B., Yang, X., \& Lü, Y. (2010). Remote sensing of ecosystem services: An opportunity for spatially explicit assessment. Chinese Geographical Science, 20(6), 522-535. http://dx.doi.org/10.1007/s11769-010-0428-y

Feng, X., Fu, B., Lu, N., Zeng, Y., \& Wu, B. (2013). How ecological restoration alters ecosystem services: An analysis of carbon sequestration in china's loess plateau. Scientific Reports, 3, 2846.

Fischer, G., Nachtergaele, F., Prieler, S., van Velthuizen, H. T., Verelst, L., \& Wiberg, D. (2008). Global Agro-ecological Zones Assessment for Agriculture (GAEZ 2008). Rome, Italy: IIASA, Laxenburg, Austria and FAO.

Fu, B. J., Liu, G. H., Lü, Y. H., Chen, L. D., \& Ma, K. M. (2004). Ecoregions and ecosystem management in China. The International Journal of Sustainable Development \& World Ecology, 11(4), 397-409. http://dx.doi.org/10.1080/ 13504500409469842

Gao, Y. N., Yu, G. R., Zhang, L., Liu, M., Huang, M., \& Wand, Q. F. (2012). The changes of net primary productivity in chinese terrestrial ecosystem: Based on process and parameter models. Progress in Geography, 31(1), 109-117, in Chinese.

Hauck, J., Görg, C., Varjopuro, R., Ratamäki, O., Maes, J., Wittmer, H., et al. (2013). Maps have an air of authority: Potential benefits and challenges of ecosystem service maps at different levels of decision making. Ecosystem Services, 4 , 25-32. http://dx.doi.org/10.1016/j.ecoser.2012.11.003

Homolová, L., Schaepman, M. E., Lamarque, P., Clevers, J. G. P. W., de Bello, F., Thuiller, W., et al. (2014). Comparison of remote sensing and plant trait-based modelling to predict ecosystem services in subalpine grasslands. Ecosphere, 5(8), 1-29. http://dx.doi.org/10.1890/ES13-00393.1

Huang, J., Chen, B., Liu, C., Lai, J., Zhang, J., \& Ma, K. (2012). Identifying hotspots of endemic woody seed plant diversity in China. Diversity and Distributions, 18 , 673-688. http://dx.doi.org/10.1111/j.1472-4642.2011.00845.x

López-Pujol, J., Zhang, F. M., \& Ge, S. (2006). Plant biodiversity in China: Richly varied, endangered, and in need of conservation. Biodiversity $\mathcal{E}$ Conservation, 15(12), 3983-4026. http://dx.doi.org/10.1007/s10531-005-3015-2

Lü, Y., Ma, Z., Zhang, L., Fu, B., \& Gao, G. (2013). Redlines for the greening of China. Environmental Science E' Policy, 33, 346-353. http://dx.doi.org/10.1016/j.envsci. 2013.05.007

Lü, Y., Zhang, L., Feng, X., Zeng, Y., Fu, B., Yao, X., et al. (2015). Recent ecological transitions in China: Greening, browning, and influential factors. Scientific Reports, 5, 8732. http://dx.doi.org/10.1038/srep08732

Lei, F., Zhao, H., \& Yin, Z. (2006). Distribution pattern of endangered bird species in China. Integrative Zoology, 1(4), 162-169. http://dx.doi.org/10.1111/j.17494877.2006.00037.X

Liu, J. Y., Zhang, Z. X., Xu, X. L., Kuang, W. H., Zhou, W. C., Zhang, S. W., et al. (2010). Spatial patterns and driving forces of land use change in China during the early 21 st century. Journal of Geographical Sciences, 20(4), 483-494. http://dx.doi. org/10.1007/s11442-010-0483-4

Liu, Y., Zhou, Y., Ju, W., Chen, J., Wang, S., He, H., et al. (2013). Evapotranspiration and water yield over China's landmass from 2000 to 2010. Hydrology and Earth System Science, 17, 4957-4980. http://dx.doi.org/10.5194/hess-17-4957-2013
Liu, J. Y., Kuang, W. H., Xu, X. L., Qin, Y. W., Ning, J., et al. (2014). Spatiotemporal characteristics, patterns and causes of land-use changes in China since the late 1980. Journal of Geographical Sciences, 24(2), 195-210. http://dx.doi.org/10. 1007/s11442-014-1082-6

Lu, Y., Tian, H., Wu, B., \& Sun, W. (2010). Spatial and temporal variability characteristics of temperature in Huai River basin during 1961-2005 based on Kriging method. Environmental Science and Information Application Technology, 4, 232-235 (ESIAT), 2010 International Conference on IEEE.

MEA (Millennium Ecosystem Assessment). (2005). Ecosystems and human well-being: Synthesis. Washington, DC: World Resources Institute.

Maes, J., Teller, A., Erhard, M., Liquete, C., Braat, L., Berry, P., et al. (2013). Mapping and Assessment of Ecosystems and their Services. An analytical framework for ecosystem assessments under Action 5 of the EU biodiversity strategy to 2020. Luxembourg: Publications office of the European Union.

Martínez-Harms, M. J., \& Balvanera, P. (2012). Methods for mapping ecosystem service supply: A review. International Journal of Biodiversity Science, Ecosystem Services $\mathcal{E}^{\prime}$ Management, 8(1-2), 17-25. http://dx.doi.org/10.1080/21513732. 2012.663792

Naidoo, R., Balmford, A., Costanza, R., Fisher, B., Green, R. E., Lehner, B., et al. (2008) Global mapping of ecosystem services and conservation priorities. Proceedings of the National Academy of Sciences of the United States of America, 105(28), 9495-9500. http://dx.doi.org/10.1073/pnas.0707823105

Oreskes, N., Shrader-Frechette, K., \& Belitz, K. (1994). Verification, validation, and confirmation of numerical models in the Earth sciences. Science, 263(5147), 641-646. http://dx.doi.org/10.1126/science.263.5147.641

Ouyang, Z., Zheng, H., Xiao, Y., Polasky, S., Liu, J., Xu, W., et al. (2016). Improvements in ecosystem services from investments in natural capital. Science, 352(6292), 1455-1459. http://dx.doi.org/10.1126/science.aaf2295

Pérez, A., Mas, J. F., Velázquez, A., \& Vázquez, L. (2008). Modeling vegetation diversity types in mexico based upon topographic features. Interciencia, 33(2), 88-95.

Petrosillo, I., Semeraro, T., Zaccarelli, N., \& Aretano, R. (2013). The possible combined effects of land-use changes and climate conditions on the spatial-temporal patterns of primary production in a natural protected area. Ecological Indicators, 29, 367-375. http://dx.doi.org/10.1016/j.ecolind.2013.01. 025

Posner, S., Verutes, G., Koh, I., Denu, D., \& Ricketts, T. (2016). Global use of ecosystem service models. Ecosystem Services, 17, 131-141. http://dx.doi.org/ 10.1016/j.ecoser.2015.12.003

Potter, C. S., Randerson, J. T., Field, C. B., Matson, P. A., Vitousek, P. M., Mooney, H. S., et al. (1993). Terrestrial ecosystem production: A process model based on global satellite and surface data. Global Biogeochemical Cycles, 7, 811-841. http://dx.doi.org/10.1029/93GB02725

Qiu, C., Shen, Z., Peng, P., Mao, L., \& Zhang, X. (2014). How does contemporary climate versus climate change velocity affect endemic plant species richness in China? Chinese Science Bulletin, 59, 4660-4667. http://dx.doi.org/10.1007/ s11434-014-0640-8

Rao, E., Ouyang, Z., Yu, X., \& Xiao, Y. (2014). Spatial patterns and impacts of soil conservation service in China. Geomorphology, 207(15), 64-70. http://dx.doi. org/10.1016/j.geomorph.2013.10.027

Richmond, A., Kaufmann, R. K., \& Mynen, R. B. (2007). Valuing ecosystem services: A shadow price for net primary production. Ecological Economics, 64, 454-462. http://dx.doi.org/10.1016/j.ecolecon.2007.03.009

Sharpley, A. N., \& Williams, J. R. (1990). EPIC-erosion/productivity impact calculator: 1. Model documentation. Technical Bulletin-United States Department of Agriculture., 1768 Pt 1.

Stürck, J., Poortinga, A., \& Verburg, P. H. (2014). Mapping ecosystem services: The supply and demand of flood regulation services in Europe. Ecological Indicators 38(3), 198-211. http://dx.doi.org/10.1016/j.ecolind.2013.11.010

Tang, Z., Wang, Z., Zheng, C., \& Fang, J. (2006). Biodiversity in China's mountains. Frontiers in Ecology and the Environment, 4(7), 347-352. http://dx.doi.org/10. 1890/1540-9295(2006)004[0347:BICM]2.0.CO;2

Trabucchi, M., Ntshotsho, P., O’Farrell, P., \& Comín, F. A. (2012). Ecosystem service trends in basin-scale restoration initiatives: A review. Journal of Environmental Management, 111, 18-23. http://dx.doi.org/10.1016/j.jenvman.2012.06.040

Wickama, J., Masselink, R., \& Sterk, G. (2015). The effectiveness of soil conservation measures at a landscape scale in the West Usambara highlands, Tanzania. Geoderma, 241-242, 168-179. http://dx.doi.org/10.1016/j.geoderma.2014.11. 020

Woodruff, S. C., \& BenDor, T. K. (2016). Ecosystem services in urban planning: Comparative paradigms and guidelines for high quality plans. Landscape and Urban Planning, 152, 90-100. http://dx.doi.org/10.1016/j.landurbplan.2016.04. 003

Wu, S., Yang, Q., \& Zheng, D. (2003). Delineation of eco-geographic regional system of China. Journal of Geographical Sciences, 13(3), 309-315.

Wu, R., Long, Y., Malanson, G. P., Garber, P. A., Zhang, S., Li, D., et al. (2014). Optimized spatial priorities for biodiversity conservation in China: A systematic conservation planning perspective. Public Library of Science, 9(7), e103783. http://dx.doi.org/10.1371/journal.pone.0103783

Xie, G., Zhang, C., Zhang, L., Su, D., Cao, S., Leng, Y., et al. (2012). China's county-scale ecological regionalization. Journal of Natural Resources, 27(1), 154-162, in Chinese.

Yu, K. J., Li, H. L., Li, D. H., Qiao, Q., \& Xi, X. S. (2009). National scale ecological security pattern. Acta Ecologica Sinica, 29, 5163-5175, in Chinese with English Abstract. 
Yuan, Q., Wu, S., Zhao, D., Dai, E., Chen, L., \& Zhang, L. (2014). Modeling net primary productivity of the terrestrial ecosystem in China from 1961 to 2005. Journal of Geographical Sciences, 24(1), 3-17. http://dx.doi.org/10.1007/s11442-0141069-3

Zagonari, F. (2016). Using ecosystem services in decision-making to support sustainable development: Critiques, model development, a case study, and perspectives. Science of the Total Environment, 548-549, 25-32. http://dx.doi. org/10.1016/j.scitotenv.2016.01.021

Zhang, Y. B., \& Ma, K. P. (2008). Geographic distribution patterns and status assessment of threatened plants in China. Biodiversity and Conservation, 17(7), 1783-1798. http://dx.doi.org/10.1007/s10531-008-9384-6

Zhang, L., Dawes, W. R., \& Walker, G. R. (2001). Response of mean annual evapotranspiration to vegetation changes at catchment scale. Water Resources Research, 37(3), 701-708. http://dx.doi.org/10.1029/2000WR900325
Zhang, L. W., Fu, B., Lü, Y., \& Zeng, Y. (2015). Balancing multiple ecosystem services in conservation priority setting. Landscape Ecology, 30, 535-546. http://dx.doi. org/10.1007/s10980-014-0106-Z

Zheng, J., Yin, Y., \& Li, B. (2010). A new scheme for climate regionalization in China. Acta Geographica Sinica, 1, 3-12, in Chinese.

Zhu, W., Pan, Y., \& Zhang, J. (2007). Estimation of net primary productivity of Chinese terrestrial vegetation based on remote sensing. Journal of Plant Ecology, 31(3), 413-424, in Chinese.

Zurlini, G., Petrosillo, I., Aretano, R., Castorini, I., D’Arpa, S., De Marco, A., et al. (2014). Key fundamental aspects for mapping and assessing ecosystem services: Predictability of ecosystem service providers at scales from local to global. Annali Di Botanica (Roma), 4, 53-63. http://dx.doi.org/10.4462/ annbotrm-11754 